\title{
Function and mechanisms of microRNA-20a in colorectal cancer (Review)
}

\author{
ZHENG XIAO $^{1,2^{*}}$, SHI CHEN ${ }^{1,2^{*}}$, SHUJUN FENG $^{1,2^{*}}$, YUKUN LI $^{1,2}$, \\ JUAN ZOU ${ }^{1,2}$, HUI LING ${ }^{1,2}$, YING ZENG ${ }^{1,3}$ and XI ZENG ${ }^{1,2}$ \\ ${ }^{1}$ Hunan Province Key Laboratory of Tumor Cellular and Molecular Pathology, Cancer Research Institute; \\ ${ }^{2}$ Hunan Province Cooperative Innovation Center for Molecular Target New Drug Study; \\ ${ }^{3}$ School of Nursing, University of South China, Hengyang, Hunan 421001, P.R. China
}

Received May 24, 2019; Accepted October 29, 2019

DOI: $10.3892 /$ etm.2020.8432

\begin{abstract}
Colorectal cancer (CRC) is the third most common malignancy and the second leading cause of cancer-associated mortality worldwide. CRC currently has no specific biomarkers to promote its diagnosis and treatment and the underlying mechanisms regulating its pathogenesis have not yet been determined. MicroRNAs (miRs) are small, non-coding RNAs that exhibit regulatory functions and have been demonstrated to serve a crucial role in the post-transcriptional regulatory processes of gene expression that is associated with cell physiology and disease progression. Recently, abnormal miR-20a expression has been identified in a number of cancers types and this has become a novel focus within cancer research. High levels of miR-20a expression have been identified in CRC tissues, serum and plasma. In a recent study, miR-20a was indicated to be present in feces and to exhibit a high sensitivity to CRC. Therefore, miR-20a may be used as a marker for CRC and an indicator that can prevent the invasive examination of patients with this disease. Changes in the expression of miR-20a during chemotherapy can be used as a biomarker for monitoring resistance to treatment. In conclusion, miR-20a exhibits the potential for clinical application as a novel diagnostic biomarker and therapeutic target for use in patients with CRC. The present study focused on the role and mechanisms of miR-20a in CRC.
\end{abstract}

Correspondence to: Professor Ying Zeng, School of Nursing, University of South China, 28 West Changsheng Road, Hengyang, Hunan 421001, P.R. China

E-mail: zengying2003@126.com

Professor Xi Zeng, Hunan Province Key Laboratory of Tumor Cellular and Molecular Pathology, Cancer Research Institute, University of South China, 28 West Changsheng Road, Hengyang, Hunan 421001, P.R. China

E-mail: zx397@126.com

*Contributed equally

Key words: colorectal cancer, microRNA-20a, biomarker, therapeutic potential, mechanism

\section{Contents}

1. Introduction

2. microRNA-20a overview

3. The mechanism of miR-20a in CRC

4. miR-20a can be used as a diagnostic marker in CRC

5. miR-20a may be used as a monitoring indicator during chemotherapy

6. Conclusion and prospects

\section{Introduction}

Colorectal cancer (CRC) is one of the most common cancers, causing the third highest cancer-associated morbidity and the second highest of cancer-associated mortality worldwide (1). According to a previous estimation, $>1.8$ million new cases of CRC and 881,000 cases of mortality occurred in 2018. According to current trends, in 2030, the incidence of colon and rectal cancers will increase by $90.0 \%$ and $124.2 \%$, respectively (1). The 5-year survival rate for patients with CRC ranges from $12.5-70.4 \%$ and the prognosis for this disease is poor (2). Due to the fact clear clinical symptoms are not commonly seen in most CRC cases and diagnostic methods with high sensitivity and accuracy are lacking, the early detection of CRC is difficult. Currently, the main treatments for CRC surgery, radiotherapy and chemotherapy. However, one-third of patients exhibit recurrent issues following radical surgery and distant metastasis $(3,4)$. Furthermore, the radiation dose is difficult to control during radiotherapy and the identification of the location of lesions in patients with CRC is required for an accurate dose to be administered (5). Additionally, resistance to chemotherapy can be easily ignored due to lack of monitoring indicators during treatment. The aforementioned issues highlight the requirement for the development of novel therapeutic treatments and the identification of predictive markers in CRC. The pathogenesis of CRC has been studied extensively, yet the mechanism governing the disease remains to be determined and this inhibits the research and development progress (6).

MicroRNA (miRNA/miR) are small noncoding RNAs that are 18-24 nucleotides (nt) in length and have been indicated to be associated with the post-transcriptional regulation of 
Table I. miRNAs reported in colorectal cancer.

\begin{tabular}{|c|c|c|c|c|}
\hline miRNAs & Expression & Target & Features & Reference \\
\hline $\mathrm{miR}-17$ & $\uparrow$ & PTEN & Invasion and migration & (11) \\
\hline miR-18a & $\uparrow$ & ATM & DNA repair & (12) \\
\hline miR-19a & $\uparrow$ & TIA1 & Proliferation and migration & (13) \\
\hline miR-19b & $\uparrow$ & ITGB8 & Growth and metastasis & (14) \\
\hline miR-20a & $\uparrow$ & $\begin{array}{l}\text { GABBR1,SMAD4, } \\
\text { SENP1, BNIP2, etc. }\end{array}$ & $\begin{array}{l}\text { Proliferation, apoptosis, invasion, } \\
\text { migration, chemo-resistance }\end{array}$ & $(15-17)$ \\
\hline miR-21 & $\uparrow$ & PDCD4 & Invasion, migration, intravasation, & (18) \\
\hline miR-30a & $\downarrow$ & Metadherin & Invasion and migration & (19) \\
\hline miR-31 & $\uparrow$ & RASA1 & Growth and proliferation & (20) \\
\hline miR-34a & $\downarrow$ & Sirt1 and E2F3 & Chemo-resistance & (21) \\
\hline miR-92a & $\uparrow$ & PTEN & Invasion and migration & (22) \\
\hline miR-99a & $\downarrow$ & KRAS & Drug resistance & (23) \\
\hline miR-128 & $\downarrow$ & SIRT1 & Apoptosis & (24) \\
\hline miR-145 & $\downarrow$ & MAP4K4 & Migration & (25) \\
\hline miR-149 & $\downarrow$ & FOXM1 & Invasion and migration & (26) \\
\hline mR-198 & $\downarrow$ & ADAM28 & Proliferation & (27) \\
\hline miR-296 & $\downarrow$ & ARRB1 & Cell growth and apoptosis & (28) \\
\hline miR-383 & $\downarrow$ & PAX6 & Proliferation and invasion & (29) \\
\hline $\operatorname{miR}-410$ & $\uparrow$ & DKK-1 & Proliferation, migration and invasion & (30) \\
\hline $\operatorname{miR}-452$ & $\uparrow$ & GSK3 $\beta$ & Proliferation and migration & $(31)$ \\
\hline miR-598 & $\uparrow$ & INPP5E & Proliferation and cell cycle & (32) \\
\hline miR-769 & $\downarrow$ & CDK1 & Proliferation, apoptosis, migration and invasion & (33) \\
\hline $\operatorname{miR} 3666$ & $\downarrow$ & SATB2 & Proliferation, migration and invasion & (34) \\
\hline miR-7702 & $\downarrow$ & TADA1 & Invasion and migration & (35) \\
\hline
\end{tabular}

$\uparrow$, up; $\downarrow$, down; miR, microRNA.

genes in CRC. Since October 2018, 38,589 miRNAs have been identified (miRBase Sequence Database). Studies have demonstrated that changes in the expression of miRNAs are associated with the majority of cellular processes within tumor pathology (7). miRNAs are regulatory RNA molecules in the genome and serve an important role in a number of physiological conditions, including cell differentiation, development, apoptosis, immune response, hematopoiesis, cell death and proliferation $(8,9)$. miRNAs function by binding to complementary sequences on the 3'-untranslated regions, or the open reading frames, of target genes to regulate gene expression at the post-transcriptional level, leading to the degradation of target mRNAs or the inhibition of mRNA translation (10).

Studies have indicated that numerous miRNAs are aberrantly expressed in CRC and regulate multiple targets (Table I) (11-35). It has been revealed that all members of the miR-17-92 cluster participate in the process of CRC. The miR-17-92 family includes miR-17, miR-18, miR-19a, miR-19b, miR-20a and miR-92a. Currently, the miR-17-92 cluster is one of the most researched miRNA clusters and is an example of a multi-sequence miRNA gene that is associated with the development of a variety of malignancies (36). miR-17 has been indicated to be overexpressed in CRC and promote the invasion and metastasis of tumors by targeting PTEN (11). High levels of miR-18a in CRC have been revealed to attenuate the repair function of DNA and induce carcinogenesis by targeting ATM to suppress ATM expression (12). The overexpression of miR-19a in CRC cells has been indicated to promote cell invasion and the epithelial-mesenchymal transition (EMT), and has been revealed to be associated with lymph node metastasis (37). In a previous study, miR-92a upregulated $\beta$-catenin and vimentin, and downregulated epithelial-cadherin, targeting PTEN induced EMT in CRC through the PTEN/phosphoinositide 3 kinase/protein kinase B pathway (22). Using the Integrating Gene Expression Omnibus DataSets portal (GEO DataSets) of 3 cohorts from different regions (GSE41655, GSE35834 and GSE48267), bioinformatics analysis has identified common changes in 14 differentially expressed miRNAs in CRC, including miR-145, miR-497, miR-30a, miR-31 and miR-20a. Target prediction of differentially expressed miRNAs has previously demonstrated that tumorigenesis is associated with a series of transcription factors. A previous study indicated that miR-20a may serve an important role in CRC, according to the network constructed by these microRNAs (38). Furthermore, miR-20a was revealed to be upregulated in the serum, plasma, tissue and fecal samples of patients with CRC, and was 
indicated to serve a role in the development of CRC and the mechanisms regulating chemotherapy resistance (39-43). The aforementioned results provide novel information regarding CRC and can aid in the development of novel target drugs for use in the treatment of this disease. In the present review, miR-20a is introduced, the mechanisms of miR-20a in CRC are elaborated on and then the potential of miR-20a as a diagnostic indicator of $\mathrm{CRC}$ is described. Additionally, the expression of miR-20a in CRC during chemotherapy is described, explaining why miR-20a may be used as a biomarker for predicting drug resistance to CRC. Finally, the research prospects of miR-20a in $\mathrm{CRC}$ are discussed.

\section{2. microRNA-20a overview}

Human miR-20a, which is located at $13 \mathrm{q} 31.3$, is also known as MIR20, MIRH1, MIRHG1, MIRN20, miR-20, MIR17HG, MIRN20A, mir-20a, C13orf25, miRNA20A, hsa-mir-20 or hsa-mir-20a.

miR-20a is an important molecule in a variety of biological processes and in cancer progression. Previous studies have shown that the serum exhibits high miR-20a expression and has been indicated to be associated with poor prognosis in patients with nasopharyngeal carcinoma and gastric cancer $(44,45)$. A study has shown that miR-20a can directly target run-related transcription factor 1 to attenuate cell-death in cervical cancer cells by preventing natural killer (NK) cells from releasing interferon- $\gamma(\mathrm{IFN}-\gamma)$ and tumor necrosis factor- $\alpha$ (TNF- $\alpha$ ), which promote tumor growth (46). miR-20a can affect RB1CC1/FIP200 cellular levels, which are associated with autophagosome formation and the regulation of the autophagy pathway in breast cancer cells (47). miR-20a can also inhibit proliferation and induce the apoptosis of hepatocellular carcinoma cells in vitro by targeting the anti-apoptotic member myeloid cell leukemia sequence 1 protein of the $\mathrm{Bcl}-2$ family (48). The expression of miR-20a in glioma, cervical cancer, gastric cancer, lung carcinoma, neuroblastoma and prostate cancer, and its corresponding target genes and their functions, are presented in Table II (46,49-68). However, the upregulation or downregulation of miR-20a expression in a number of tumors is not consistent in numerous previous studies due to the differences in cell lines and limited sample sizes (47,69-79). The current review article outlines the role of miR-20a in CRC and provides information that can be used in future research on miR-20a.

\section{The mechanism of miR-20a in CRC}

Increasing data has suggested that miR-20a serves a key role in $\mathrm{CRC}$ and its diverse functions in relation to carcinogenesis of CRC, including anti-apoptotic, EMT, migration, invasion and senescence, have recently been focused on (Fig. 1).

miR-20a participates in anti-apoptosis of CRC. A previous study demonstrated that TNF-related apoptosis-inducing ligand (TRAIL) -induced apoptosis is associated with a higher expression of miR-20a in CRC SW480 cells compared with the normal colorectal epithelial cell line FHC (15). Mitochondrial apoptosis, that is induced by a combination of the knockdown miR-20a and TRAIL, depends on the upregulation of $\mathrm{BH} 3$ interacting domain death agonist (BID). The knockdown of miR-20a was indicated to inhibit the translocation of truncated BID (tBID) into the mitochondria, which induced the mitochondrial pathway of apoptosis. TRAIL is a TNF superfamily member that can selectively induce apoptosis in cancer cells and induce exogenous apoptosis, however TRAIL is associated with the activation of caspase-8 (80). BID, which is a pro-apoptotic member of the Bcl-2 family, serves as a bridge between death receptor signaling and mitochondrial apoptosis (81). Following the interaction between the death receptor and the ligand, BID is cleaved by cystatin- 8 into an activated form, tBID (82). The translocation of tBID to the mitochondria is followed by mitochondrial outer membrane permeabilization and depolarization (83), leading to the activation of caspase-9, caspase-3 and apoptotic effects (80). Furthermore, the activation of caspase- 9 and caspase- 3 has been demonstrated to be initiated by caspase- 8 activation. The knockdown of miR-20a in SW480 cells has been revealed to increase the antitumor effect of TRAIL through the caspase- 8 dependent pathway (15). miR-20a regulates BID apoptotic genes that are associated with TRAIL sensitivity of CRC and therefore anti-miR-20a is a promising target to promote apoptosis.

miR-20a promotes EMT and the migration and invasion of $C R C$. During EMT, cancer cells lose epithelial characteristics to form migratory and invasive mesenchymal cell phenotypes, leading to the consideration that EMT is a prologue to cancer cell invasion and migration. By promoting EMT, miR-20a aids the detachment of CRC cells from the tissue parenchyma and their entry into systemic circulation during cancer metastasis. Studies have indicated that miR-20a induced EMT by inhibiting mothers against decapentaplegic homolog 4 (Smad4) expression via direct targeting of Drosophila Smad4 3'-untranslated region (UTR), whereas the overexpression of Smad4 abolished EMT that was mediated by miR-20a overexpression. Furthermore, among a variety of miRNAs, miR-20a has been indicated to exhibit the highest potential for binding to 3'-UTR of Smad4, which is a central signal transduction element of the transforming growth factor (TGF) superfamily and its mutation leads to a functional transition of TGF- $\beta$ into a tumor promoter $(84,85)$. Early carcinogenesis is caused by WNT signaling activation and TGF- $\beta$ inactivation. Additionally, experiments have indicated that miR-20a interfered with the colonic epithelium homeostasis by disrupting the regulation of Myc/p21 via TGF- $\beta$. Research has also revealed that miR-20a enhances EMT by modulating the expression of tissue inhibitor of metalloproteinases-2 (TIMP2) and matrix metalloproteinase 9 (MMP9), and that the overexpression of miR-20a inhibits the expression of TIMP2 and induces the expression of MMP2 and MMP 9 to promote EMT (16).

However, EMT can also lead to decreased cell adhesion, cytoskeletal dynamics, morphological changes and increased invasion and migration ability (86). The overexpression of miR-20a has been revealed to promote migration and invasion in CRC cells and to be inversely correlated with Smad4 levels (85). Longqiu et al (87) demonstrated that miR-20a was upregulated in HCT116 and HT-29 cells (CRC lines). Through specifically binding to the 3'-UTR of $\gamma$-amino-butyric acid type $B$ receptor 1 (GABBR1), miR-20a downregulated the expression of GABBR1 and promoted proliferation and invasion. 


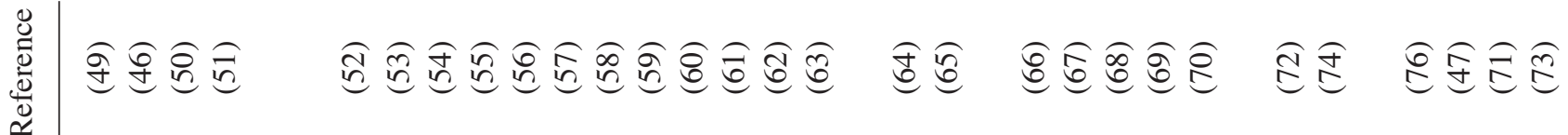

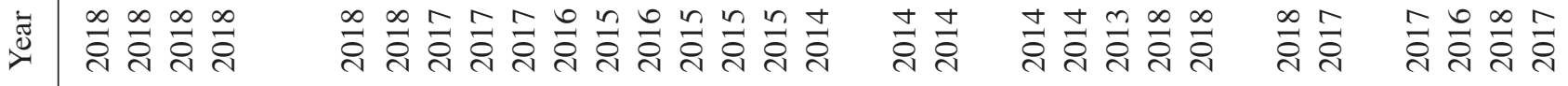

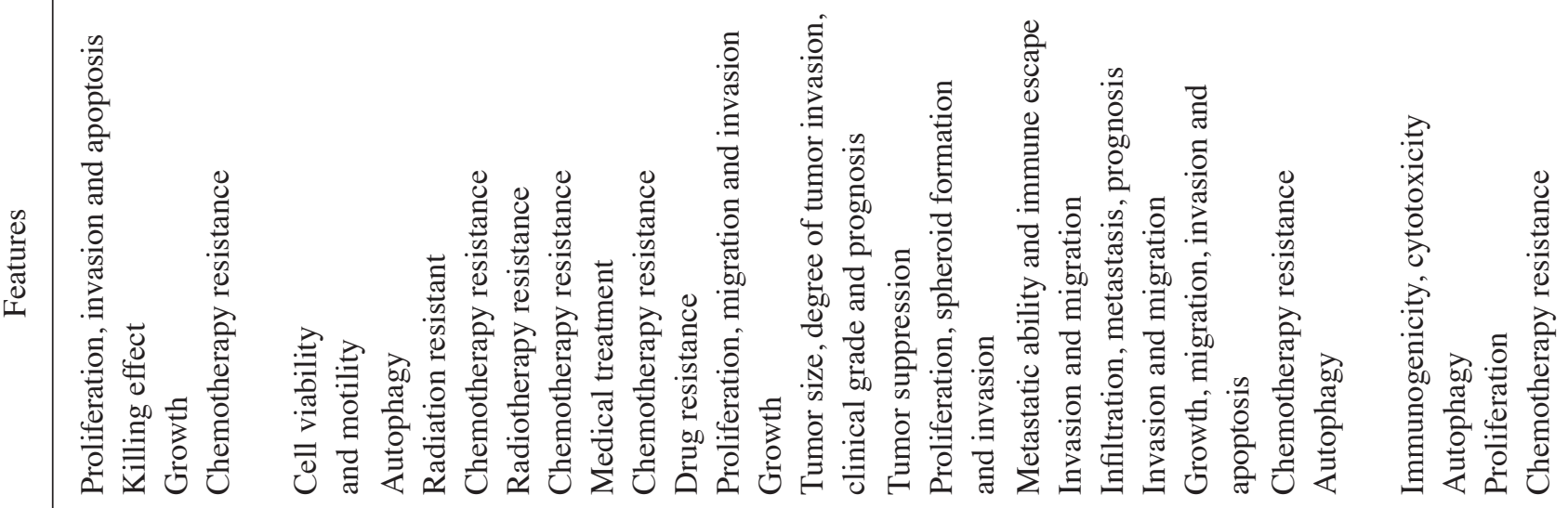

荡

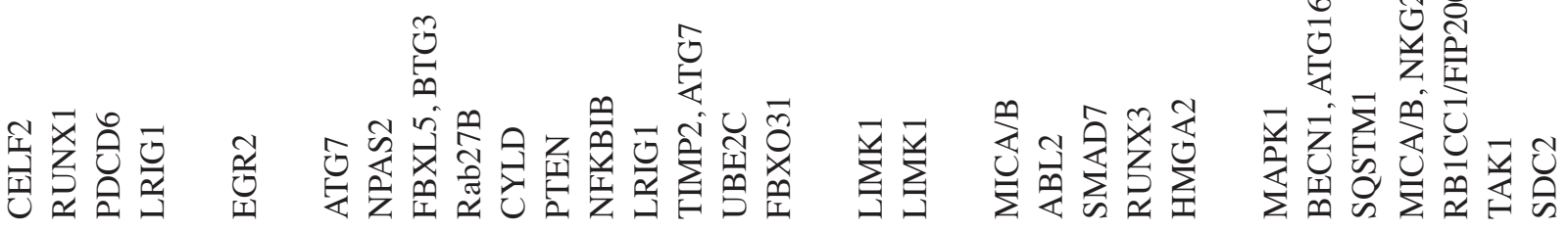

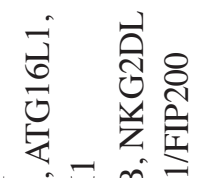

$\leftarrow \leftarrow \leftarrow \leftarrow$

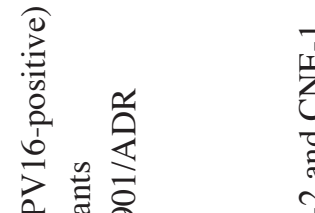

ज.

胥

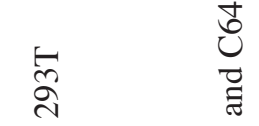

ֻิ

$\overrightarrow{\text { तิ }}$

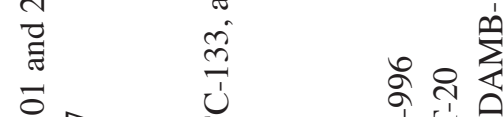

के

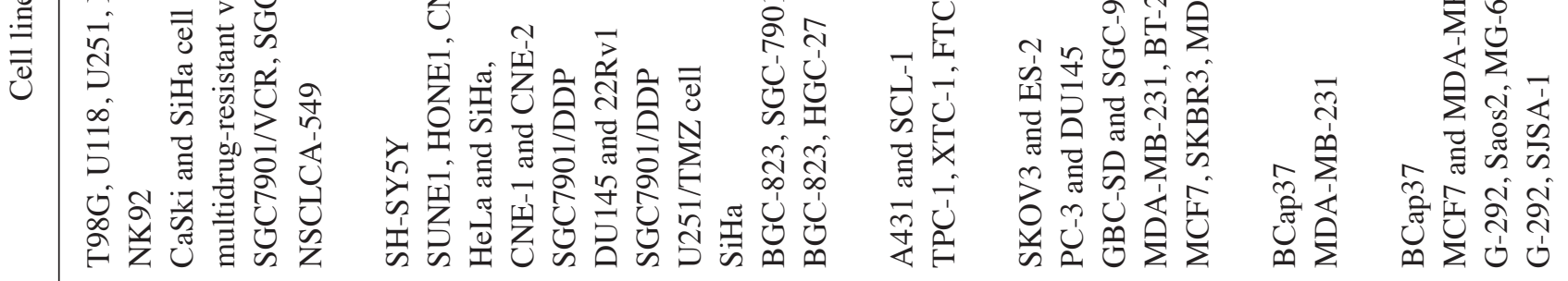

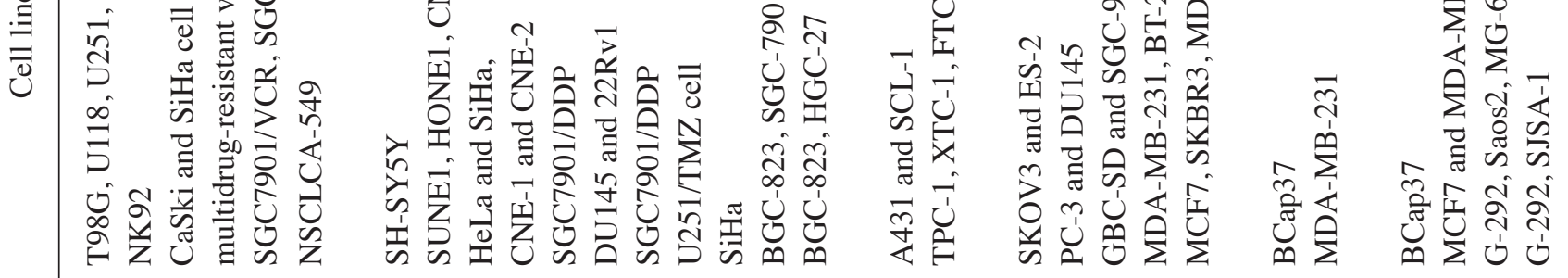

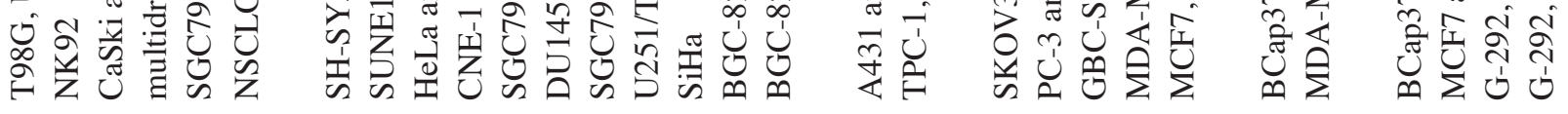




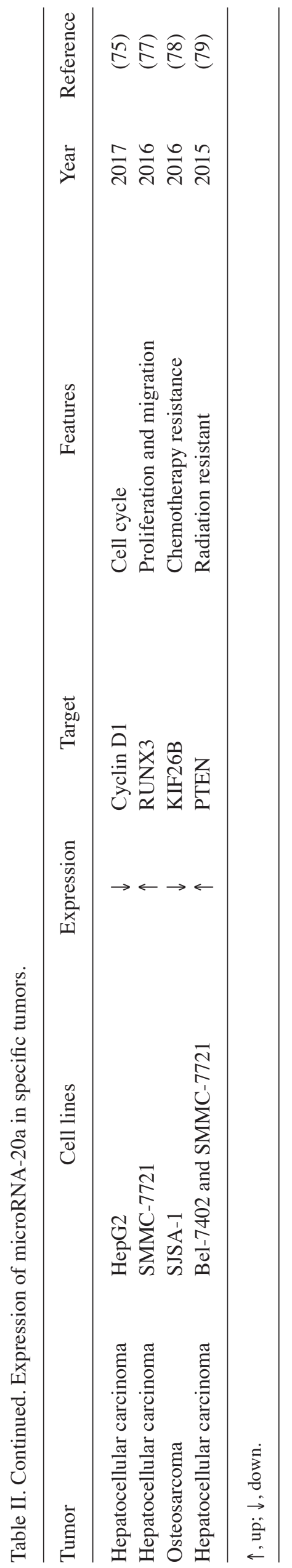

GABBR1 is a 7-transmembrane receptor and its expression is indicated to be decreased in CRC tissues $(88,89)$. A study has shown that the overexpression or activation of GABBR1 inhibited the proliferation and invasion of CRC HCT116 cells, indicating GABBR1 may be a target for use in CRC treatment. These results indicated that miR-20a may function through the downregulation of GABBR1 to promote cell proliferation and invasion, leading to CRC. However, the validity of this mechanism requires verification in several other CRC cell lines.

In conclusion, miR-20a has been revealed to participate in EMT by regulating Smad4 and TIMP2. During the EMT process, miR-20a can also regulate GABBR1 to increase CRC invasion and metastasis. Further study of miR-20a in CRC may provide new research prospects for the mechanisms regulating EMT.

miR-20a induces cells senescence of CRC. In colibactin-producing Escherichia coli (pks $+E$. coli) infected intestinal epithelial cells, miR-20a has been indicated to be significantly upregulated and to induce cell senescence through targeting Sentrin-specific protease 1 (SENP1), thereby enhancing the invasiveness of CRC cells (90). miR-20a has been revealed to bind to the 3'-UTR of SENP1 mRNA and this was indicated using a reporter gene assay in pks $+E$. coli infected cells. SENP1 is a key enzyme that controls the process of small ubiquitin-like modifier (SUMO) (90). SENP1 overexpression significantly reduces the number of senescent cells induced by pks $+E$. coli infection. Long-term symbiotic bacteria, which produce metabolites or toxins, directly damage host DNA and cause chronic inflammatory stress, serve a role in epithelial cell chronic injury and constitute a potential etiological component of sporadic CRC (91). E. coli (pks + E. coli) is a component of the gut microbiota that stimulates inflammation and DNA damage and causes mutations and chromosomal instability to promote cancer development. $\mathrm{Pks}+E$. coli induce intestinal epithelial cell senescence as a result of the accumulation of SUMO-conjugated p53, which is associated with the decreased expression of SENP1. The modification of p53 by SUMO can promote the transcriptional activity of $\mathrm{p} 53$, facilitating p53-mediated cell senescence and the abnormal reduction of p53 SUMO in cells can lead to abnormalities of p53 tumor suppressor function, leading to tumorigenesis (92). $\mathrm{PksC}+$ $E$. coli induced growth factor secretion is present in senescent cells. Growth factors are a key determinant of colon cancer progression and serve as a marker of poor prognosis, in addition to serving as a target for CRC treatment and leading to the proliferation of cancer cells. $\mathrm{PksC}+E$. coli infection induces DNA damage and subsequently induces an increase in c-Myc expression, leading to c-Myc binding to the miR-20a promoter to regulate miR-20a. These senescent cells produce growth factors that can stimulate tumor growth (17). Therefore, even though miR-20a negatively regulates SENP1, the accumulation of SUMO binding p53 induces senile cells to produce growth factors, resulting in the proliferation of tumor cells.

\section{4. miR-20a can be used as a diagnostic marker in CRC}

To reduce the high morbidity and mortality observed in patients with CRC, the identification of novel biomarkers is urgently required. Observing the expression of miRNAs in CRC and the development of diagnostic markers has become a priority 


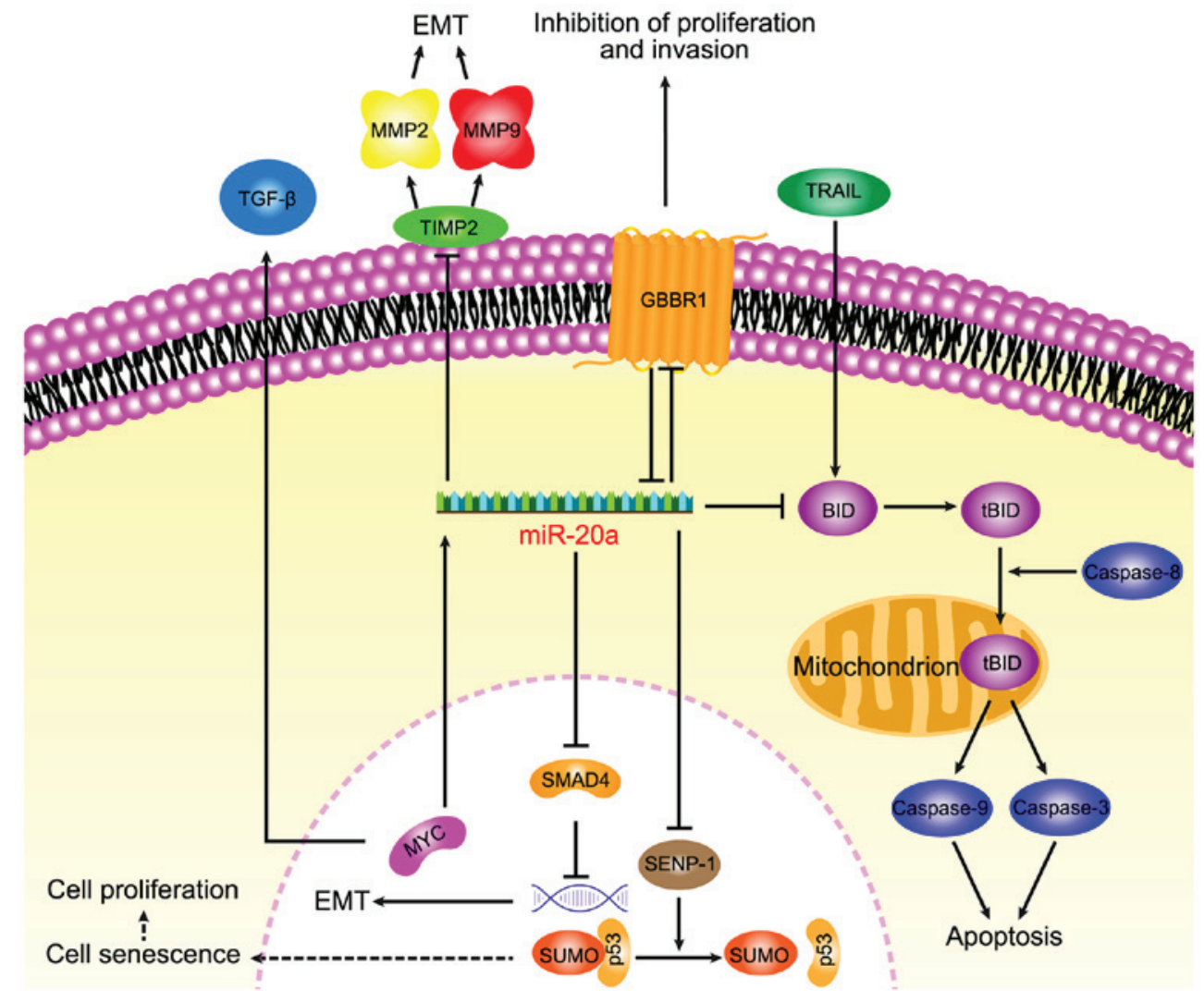

Figure 1. miR-20a downregulates GABBR1 to promote colorectal cancer proliferation and invasion and miR-20a is associated with TRAIL-induced apoptosis by targeting BID; miR-20a promotes epithelial mesenchymal transition by targeting SMAD4 and TIMP; miR-20a targets SENP1 induce cell senescence to stimulate tumor growth. miR, microRNA; SMAD4, mothers against decapentaplegic homolog 4; tBID, truncated BH3 interacting domain death agonist; SENP-1, Sentrin-specific protease 1; MMP, matrix metalloproteinase; TGF- $\beta$, transforming growth factor; TIMP, metalloproteinase inhibitor 1 ; TRAIL, TNF-related apoptosis-inducing ligand; GABBR1, $\gamma$-amino-butyric acid type B receptor 1.

in current research (93). Slattery et al (94) analyzed large sample data and demonstrated that $>86 \%$ of the differentially expressed miRNAs between CRC tissues and normal mucosa are present in $80 \%$ of the population. Tan et al (95) indicated that although the difference in miRNA levels in ulcerative colitis was not significant in mouse experiments, in CRC significant changes were observed in miRNAs and the upregulation of miR-20a in CRC tissues was higher compared with normal tissues. Analysis of the expression profiles of miRNAs between tissues from patients with CRC and normal mucosa revealed that miR-20a was an important miRNA with a high predictive value for cancer $(94,96,97)$. Analysis of 20 pairs of CRC tissues and adjacent tissues also indicated that miR-20a was differentially expressed between tissues (98). The level of miR-20a is enhanced in CRC tissues and its expression level has been indicated to be positively correlated with histological markers (including Ki-67 and cluster of differentiation 34) (99). High levels of miR-20a predict poor prognosis in patients with CRC and particularly in patients with tumor recurrence (85).

Previously, studies have indicated that the level of miR-20a in the serum and plasma of patients with CRC increased and was associated with late stage CRC $(100,101)$. The results of custom miScript miRNA PCR array analysis of 100 CRC cases, performed by Zekri et al (102), demonstrated that miR-20a was significantly increased in the serum of female patients with CRC. The selective detection of small RNA expression in blood samples from 74 patients with stage
II-IV CRC and 32 healthy controls indicated that miR-20a increased significantly in patients with CRC, and plasma levels increased in accordance with the extent of malignancy (103). Liu et al (98) demonstrated that miR-20a exhibits a diagnostic value for CRC following the comprehensive analysis of GEOs and The Cancer Genome Atlas databases. miR-20a in the serum of patients with CRC is increased compared with healthy patient serum. Furthermore, reverse transcription quantitative (RT-q)-PCR analysis of samples from 15 patients with CRC indicated that the levels of circulating miR-20a in plasma samples were significantly reduced following surgical resection. Despite these outcomes not supporting the results of a previous study (104), the staging and grading of tumors should be taken into consideration to determine whether miR-20 is a novel marker for CRC. A larger sample size is required for future research. These aforementioned studies provided new insight for use in the diagnosis and monitoring of CRC, and indicated that miR-20a is a promising serum and plasma marker in CRC.

The fecal immunochemical test is a new technique that is used to detect CRC (105). miRNAs identified in fecal samples are stable at $4^{\circ} \mathrm{C}$ and at room temperature (76). Quantitative changes in the expression of several mature miRNAs in feces may provide a more sensitive and specific non-invasive diagnostic method for CRC. In a previous study, miR-20a was selected in a total of $40 \mathrm{CRC}$ tissues and 595 fecal samples were analyzed using TaqMan probe-based RT-qPCR. miR-20a 
exhibited a significant increase in CRC fecal samples and the levels of miR-20a in feces exhibited no significant difference regardless of the proximal or distal location of cancer tissue. Additionally, the use of antibiotics did not affect fecal miR-20a levels. Therefore, fecal miR-20a can be used as a potentially non-invasive screening biomarker for CRC $(42,106)$.

\section{5. miR-20a may be used as a monitoring indicator during chemotherapy}

Chemotherapy is the widely used treatment for patients with CRC, especially in patients with metastatic CRC. Adjuvant chemoradiotherapy following surgery is also a widely used treatment, leading to a high cure rate and increased positive patient prognosis. The association between miRNA and chemotherapy has been reported in a variety of diseases, for example miR-21 antisense oligonucleotide has been indicated to increase the sensitivity of cholangiocarcinoma cells to gemcitabine (107), miR-15b and miR-16 have been revealed to regulate multidrug resistance by targeting $\mathrm{Bcl} 2$ in gastric cancer cells (108) and miR-451 has been demonstrated to downregulates multidrug resistance 1 and induces breast cancer cell resistance to doxorubicin (109). Furthermore, miRNAs are associated with the expression of a number of target genes that are related to chemosensitivity or the sensitivity of drugs to cancer cells (110). Therefore, identifying an indicator to monitor CRC chemotherapy is important and recent studies have indicated that miR-20a can be used as a monitoring indicator for chemotherapy $(111,112)$.

miR-20a is differentially expressed before and after chemotherapy. Due to the difference in the location of colon cancer and rectal cancer, the corresponding treatment will often differ. A study has demonstrated that miR-20a and a number of miRNAs are reliable prognostic predictors for patients with stage II colon cancer (101). For advanced rectal cancer, preoperative chemoradiotherapy (CRT) can improve overall survival and reduce the local recurrence rate. The reduced expression of circulating miR-20a is inversely associated with negative postoperative lymph nodes, which may contribute to the stratification of the entire mesorectal surgery. Preoperative CRT blood circulating miR-20a can be used as a marker to indicate lymph node status of patients with locally advanced rectal cancer following neoadjuvant CRT. Additionally, the differential regulation of miR-20a before and after radiotherapy and chemotherapy, in patients with rectal cancer, may be used as a marker for monitoring tumor response before and after radiotherapy and chemotherapy (113-115).

miR-20a can be used as a marker to predict and improve chemotherapy resistance of $C R C$. Chemotherapy resistance is the main cause of treatment failure in patients with cancer, especially in patients with advanced cancer. miRNAs can serve as potential biomarkers for predicting therapeutic responses in $\mathrm{CRC}$ and are major regulators of CRC drug resistance (116). miR-20a is associated with resistance to chemotherapy in a variety of cancer types, including in cancers of the digestive system (113). A previous study demonstrated that the expression of miR-20a in patients exhibiting chemoresistant CRC was significantly upregulated compared with patients that exhibited chemosensitive CRC (117). Therefore, miR-20a may be used as a biomarker for predicting the chemical sensitivity of CRC.

Platinum-based chemotherapy is one of the most important strategies for the treatment of CRC. Cisplatin is widely used in the treatment of CRC and exhibits a number of anticancer activities (118). However, the chemotherapy resistance of CRC cells is challenge in the treatment of patients with CRC (119). Studies have indicated that miR-20a induces cisplatin resistance in numerous cancers, potentially including in CRC $(55,57,111,112)$. The miR-20a inhibitor can sensitize cisplatin-induced CRC cytotoxicity via the reactive oxygen species (ROS) pathway. ROS induce apoptosis during drug treatments and can also exhibit an effect on the chemosensitivity of cancer cells (111). In combination therapy with an miR-20a inhibitor and cisplatin, ROS production is important for the death of CRC cells. ASK1 is a key mediator in the ROS-dependent cell death pathway and the knockdown of miR-20a upregulates ASK1 expression and promotes cisplatin-dependent phosphorylation of ASK1. Treatment to knockdown miR-20a can increase the expression of ASK1 to enhance ROS-dependent cell death. A combination of cisplatin and anti-miR-20a have been revealed to significantly increased JNK activation and subsequent mitochondrial apoptosis in CRC cells. Therefore, cisplatin-induced mitochondrial apoptosis is promoted by the ROS/ASK1/JNK pathway through combination with anti-miR-20a in CRC. Furthermore, the introduction of an miR-20a inhibitor eliminates cisplatin resistance and enhances the anti-tumor effect of cisplatin in vivo (112).

Fluorouracil, oxaliplatin and teniposide are additional chemotherapeutic agents that are used for CRC therapy and miR-20a has been indicated to regulate the sensitivity of these drugs. The overexpression of miR-20a exhibits resistance to these drugs in CRC. Furthermore, miR-20a directly downregulates BNIP2 mRNA and BNIP2 protein levels by binding to BNIP2 3' UTR to increase the resistance of CRC cells. BNIP2 is a proapoptosis factor, which is a member of the BCL-2 protein family (120). Therefore, miR-20a serves a role in multidrug resistance in CRC cells and may be a therapeutic target for anti-chemotherapeutic drug resistance in CRC (121).

\section{Conclusion and prospects}

The incidence of CRC has been increasing in recent years and many patients are in advanced stages of the disease. The early detection and treatment of CRC is important for controlling the progression of the disease. A number of studies have demonstrated that miRNA can be used as a biomarker for the diagnosis and prognosis of CRC, and this can provide information on tumor initiation, development, invasion, metastasis and response to chemotherapy $(16,39,111,112,122,123)$. A number of studies have also confirmed that miR-20a is significantly upregulated and serves an important role in the development, progression and therapeutic response of $\mathrm{CRC}$, and it can be used as a biomarker for CRC in tissues, serum and fecal samples (124). miR-20a has indicated efficacy in predicting risk of CRC recurrence and is associated with low survival rates $(125,126)$. Furthermore, miR-20a has been revealed to promote CRC through an association with anti-apoptosis mechanisms, EMT, migration, invasion and senescence, indi- 

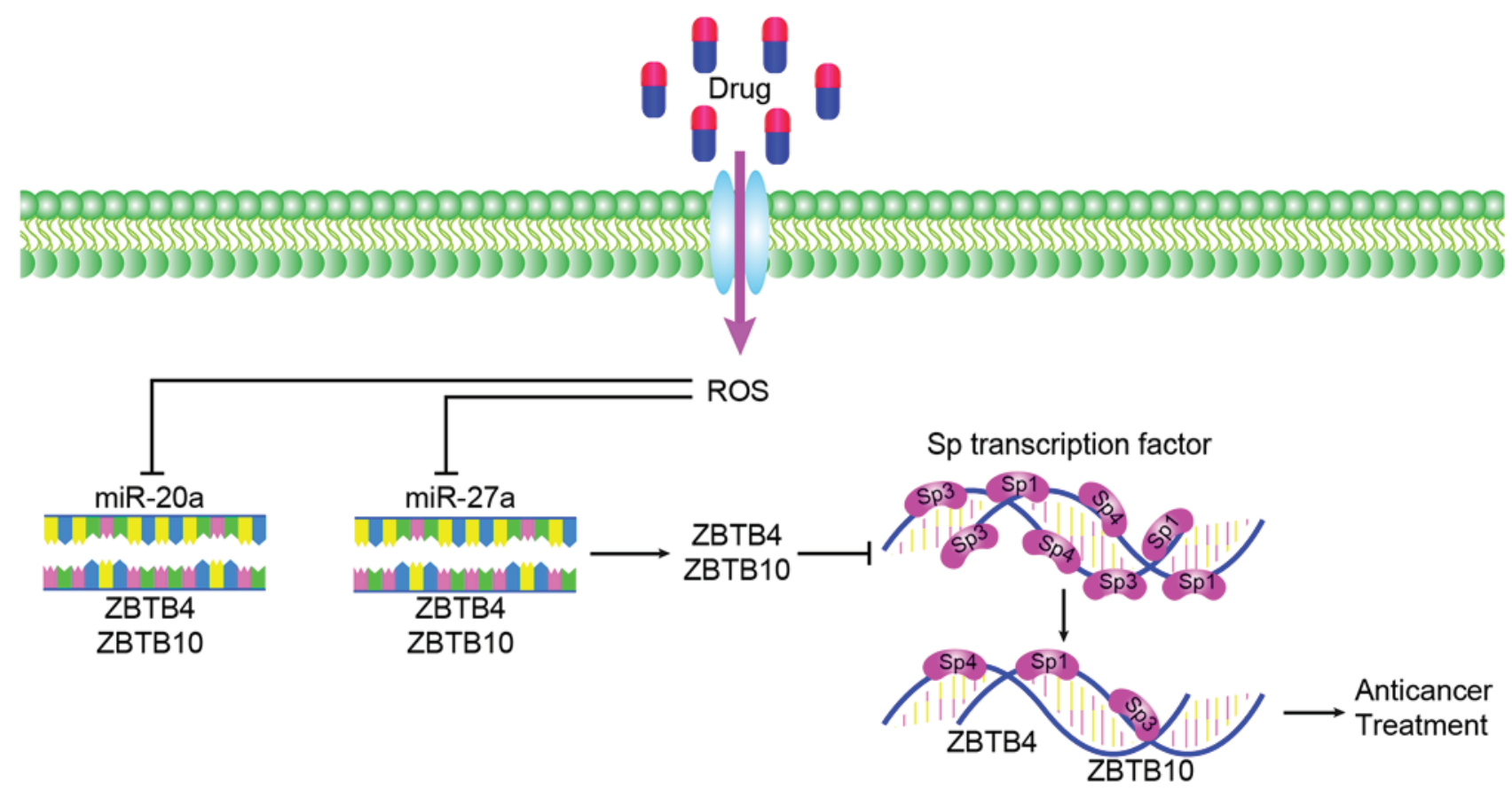

ATGC

Curcumin and RL197

Figure 2. Drugs downregulate miR-27a and miR-20a, disrupt miR-ZBTB10 and miR-ZBTB4 axes in the colon, reduce SP regulatory proteins, and exert anticancer effects. miR, microRNA; ROS, reactive oxygen species.

cating it to be a promising therapeutic target for use in the treatment of CRC. Chemotherapy is a widely used treatment in patients with CRC, however resistance can occur and the mechanisms behind this are undetermined. miR-20a has been indicated to be an effective indicator in monitoring response to treatment $(112-115,121)$. Furthermore, carcinoembryonic antigen (CEA) is a common tumor marker in gastrointestinal cancer, but its specificity and sensitivity are low. The combination of miR-20a with CEA and CA19-9 can improve the sensitivity and specificity of CEA, allowing patients to obtain the most accurate prognosis (127).

Currently, the targeted therapeutic drugs for CRC, which are used clinically, can be classified into two types. One is cetuximab and panitumumab, which target epidermal growth factor receptor and bevacizumab, regorafenib, aflibercept and ramucirumab, which target vascular endothelial growth factor. Although research into molecular targeted therapies is increasing, a large number of genes have been associated with tumor development and it is difficult to determine the genes that serve a leading role in a number of different stages in development. Molecular targeted therapy also exhibits the problem of multi-target combination therapy. Currently, the types of drugs available for clinical use are limited but exhibit great development potential. miR-20a serves an important role in the treatment and drug resistance of CRC. In anticancer therapy, miR-20a can inhibit the $\mathrm{Sp}$ repressor ZBTB4 and enhance the expression of Sp transcription factor. Anti-colon cancer drugs have been revealed to eradicate the miR-20a-ZBTB4 and miR-ZBTB10 axes within the colon by targeting SP regulators and SP transcription factors. Subsequently, Sp transcription factors and Sp-regulated genes competitively bind to GC-rich sites on their promoter sequences and induce the downregulation of Sp proteins and
Sp-dependent genes. After disruption of the miR-20a-ZBTB4 axis, ZBTB10 and ZBTB4 serve as transcriptional inhibitors of the SP regulatory gene, which can reduce $\mathrm{Sp} 1, \mathrm{Sp} 3, \mathrm{Sp} 4$ and $\mathrm{SP}$ regulatory proteins to inhibit the growth, proliferation, survival, angiogenesis and metastasis of cancer (Fig. 2). These regulatory proteins include curcumin and a synthetic analog of curcumin, (3E,5E)-3,5-bis (2,5-dimethoxybenzylidene)-1-tertbutoxycarbonylpiperidin-4-one (RL197) $(128,129)$. Sorafenib is a multi-kinase inhibitor that is currently approved for the treatment of liver, kidney and thyroid cancer. Studies have indicated that miR-20ain CRC cell lines exhibit significant changes before and after treatment with sorafenib and may become an inhibitor of CRC (130). miR-20a is associated with chemoresistance, which provides a new direction for studying anti-transformation resistance (121). Therefore, the development of drugs for the treatment of CRC based on miR-20a is promising. In CRC, over-expression and knocking down of miR-20a followed by high-throughput screening could be applied to discover downstream target genes. This method can identify molecules that regulate the expression of miR-20a in CRC cells and thus find drug targeting molecules for the CRC. Part of mechanisms of CRC indicated that miR-20a induces high expression of certain proteins and low expression of some proteins, making high expression protein inhibitors a promising treatment for CRC. As mentioned above, miR-20a can inhibit TIMP2 expression, induce expression of both MMP2 and MMP9 to promote the occurrence of EMT (16). Whether CRC can be treated by inhibiting MMP2 and MMP9 is also worth discussing. Since miR-20a is a cancer-promoting factor in CRC, specific inhibition could be considered as a potential method for the treatment of CRC. However, specifically targeting miR-20a is technically difficult. Recent studies have found that circular (circ) RNA can selectively bind to miRNA 
as a sponge $(131,132)$. circRNA binding to miRNA can be predicted by bioinformatics analysis and the screened circRNA can be used as a therapeutic strategy for miRNA (133). For example,circ_0009910 inhibits cell proliferation and promotes apoptosis through negative regulation of miR-20a in acute myeloid leukemia (AML) cells, which may become a potential therapeutic target for future AML treatment (134). In addition, long noncoding (lnc) RNA can interact with miRNA as an competitive endogenous RNA to participate in the regulation of target gene expression (135). For example, lncRNA MEG3 can competently bind to miR-23a to regulate the expression of apoptotic protease activating factor- 1 and thus regulate the progression of laryngeal cancer (136). Therefore, the establishment of IncRNA-miRNA-mRNA or circRNA-miRNA-RNA pathway in $\mathrm{CRC}$ is expected to provide a new direction for the treatment of CRC in the future (137).

Therefore, further study into the molecular mechanisms and functions of the miR-20a network is required for use in clinical practice. Elucidating the mechanism of elevated miR-20a expression in cancer, of miR-20a's association with chemotherapy resistance, the mechanism network of miR-20a promoting cancer, systemic effects and the side effects of anti-miRNA therapy, require further investigation. Furthermore, the presence of miRNAs in serum, plasma and other body fluids (including the saliva, urine and amniotic fluid) encourages the study of miRNAs, and the detection of miR-20a in these indicates that this miRNA may be used as a non-invasive biomarker for early detection and monitoring of disease progression. An increased amount of data is required to identify miR-20a in fecal, blood and other screenings, and this will provide evidence that will increase attention and lead to the assessment of the potential utility of miRNAs in clinical practice.

\section{Acknowledgements}

The authors would like to thank Prof. Qian Tao, Department of Clinical Oncology, the Chinese University of Hong Kong, for their comments on the manuscript.

\section{Funding}

The present study was funded by the National Natural Science Foundation of China (grant no. 81101643), the Natural S cience Foundation of Hunan Province of China (grant no. 2019JJ50521), the Hunan Province Cooperative Innovation Center for Molecular Target New Drug Study (2014-405) and the Foundation of the Construct Program of the Key Discipline in Hunan Province of China (2011-76).

\section{Availability of data and materials}

Not applicable.

\section{Authors' contributions}

$\mathrm{XZ}$ and $\mathrm{YZ}$ designed the present study. ZX and SC prepared and wrote the manuscript. SF and YL revised the manuscript. JZ and HL performed a literature search and selected the studies to be included. All authors approved the final version of the article.

\section{Ethics approval and consent to participate}

Not applicable.

\section{Patient consent for publication}

Not applicable.

\section{Competing interests}

The authors declare that they have no competing interests.

\section{References}

1. Bray F, Ferlay J, Soerjomataram I, Siegel RL, Torre LA and Jemal A: Global cancer statistics 2018: GLOBOCAN estimates of incidence and mortality worldwide for 36 cancers in 185 countries. CA Cancer J Clin 68: 394-424, 2018.

2. Siegel R, Desantis C and Jemal A: Colorectal Cancer Statistics, 2014. CA Cancer J Clin 64: 104-117, 2014.

3. Lan YT, Chang SC, Yang SH, Lin CC, Wang HS, Jiang JK, Chen WS, Lin TC, Chiou SH and Lin JK: Comparison of clinicopathological characteristics and prognosis between early and late recurrence after curative surgery for colorectal cancer. Am J Surg 207: 922-930, 2014.

4. Guraya SY: Pattern, stage, and time of recurrent colorectal cancer after curative surgery. Clin Colorectal Cancer 18: e223-e228, 2019.

5. Makishima H, Yasuda S, Isozaki Y, Kasuya G, Okada N Miyazaki M, Mohamad O, Matsufuji N, Yamada S, Tsuji H, et al; Liver Cancer Working Group: Single fraction carbon ion radiotherapy for colorectal cancer liver metastasis: A dose escalation study. Cancer Sci 110: 303-309, 2019.

6. Chen H, Xu Z and Liu D: Small non-coding RNA and colorectal cancer. J Cell Mol Med 23: 3050-3057, 2019.

7. Krol J, Loedige I and Filipowicz W: The widespread regulation of microRNA biogenesis, function and decay. Nat Rev Genet 11: 597-610, 2010.

8. Bartel DP: MicroRNAs: Genomics, biogenesis, mechanism, and function. Cell 116: 281-297, 2004.

9. Kim VN, Han J and Siomi MC: Biogenesis of small RNAs in animals. Nat Rev Mol Cell Biol 10: 126-139, 2009.

10. Xi XP, Zhuang J, Teng MJ, Xia LJ, Yang MY, Liu QG and Chen JB: MicroRNA-17 induces epithelial-mesenchymal transition consistent with the cancer stem cell phenotype by regulating CYP7B1 expression in colon cancer. Int J Mol Med 38: 499-506, 2016.

11. Fang L, Li H, Wang L, Hu J, Jin T, Wang J and Yang BB: MicroRNA-17-5p promotes chemotherapeutic drug resistance and tumour metastasis of colorectal cancer by repressing PTEN expression. Oncotarget 5: 2974-2987, 2014.

12. Wu CW, Dong YJ, Liang QY, He XQ, Ng SS, Chan FK, Sung JJ and $\mathrm{Yu}$ J: MicroRNA-18a attenuates DNA damage repair through suppressing the expression of ataxia telangiectasia mutated in colorectal cancer. PLoS One 8: e57036, 2013

13. Liu Y, Liu R, Yang F, Cheng R, Chen X, Cui S, Gu Y, Sun W, You C, Liu Z, et al: miR-19a promotes colorectal cancer proliferation and migration by targeting TIA1. Mol Cancer 16: 53, 2017.

14. Huang L, Cai JL, Huang PZ, Kang L, Huang MJ, Wang L and Wang JP: miR 19b-3p promotes the growth and metastasis of colorectal cancer via directly targeting ITGB8. Am J Cancer Res 7: 1996-2008, 2017.

15. Huang G, Chen X, Cai Y, Wang X and Xing C: miR-20a-directed regulation of BID is associated with the TRAIL sensitivity in colorectal cancer. Oncol Rep 37: 571-578, 2017.

16. Xu T, Jing C, Shi Y, Miao R, Peng L, Kong S, Ma Y and Li L: microRNA-20a enhances the epithelial-to-mesenchymal transition of colorectal cancer cells by modulating matrix metalloproteinases. Exp Ther Med 10: 683-688, 2015.

17. Dalmasso G, Cougnoux A, Delmas J, Darfeuille-Michaud A and Bonnet R: The bacterial genotoxin colibactin promotes colon tumor growth by modifying the tumor microenvironment. Gut Microbes 5: 675-680, 2014.

18. Asangani IA, Rasheed SA, Nikolova DA, Leupold JH, Colburn NH, Post S and Allgayer H: MicroRNA-21 (miR-21) post-transcriptionally downregulates tumor suppressor Pdcd4 and stimulates invasion, intravasation and metastasis in colorectal cancer. Oncogene 27: 2128-2136, 2008. 
19. Jin H, Shi X, Zhao Y, Peng M, Kong Y, Qin D and Lv X: MicroRNA-30a mediates cell migration and invasion by targeting metadherin in colorectal cancer. Technol Cancer Res Treat 17: 1533033818758108, 2018

20. Sun D, Yu F, Ma Y, Zhao R, Chen X, Zhu J, Zhang CY, Chen J and Zhang J: MicroRNA-31 activates the RAS pathway and functions as an oncogenic microRNA in human colorectal cancer by repressing RAS p21 GTPase activating protein 1 (RASA1). J Biol Chem 288: 9508-9518, 2013.

21. Akao Y, Noguchi S, Iio A, Kojima K, Takagi $T$ and Naoe T: Dysregulation of microRNA-34a expression causes drug-resistance to 5-FU in human colon cancer DLD-1 cells. Cancer Lett 300: 197-204, 2011.

22. Zhang G, Zhou H, Xiao H, Liu Z, Tian H and Zhou T: MicroRNA-92a functions as an oncogene in colorectal cancer by targeting PTEN. Dig Dis Sci 59: 98-107, 2014.

23. Cappuzzo F, Sacconi A, Landi L, Ludovini V, Biagioni F, D'Incecco A, Capodanno A, Salvini J, Corgna E, Cupini S, et al: MicroRNA signature in metastatic colorectal cancer patients treated with anti-EGFR monoclonal antibodies. Clin Colorectal Cancer 13: 37-45.e4, 2014.

24. Lian B, Yang D, Liu Y, Shi G, Li J, Yan X, Jin K, Liu X, Zhao J, Shang W, et al: miR-128 Targets the SIRT1/ROS/DR5 Pathway to Sensitize Colorectal Cancer to TRAIL-Induced Apoptosis Cell Physiol Biochem 49: 2151-2162, 2018.

25. Salem SM, Hamed AR, Fayez AG and Nour Eldeen G: Non-target genes regulate miRNAs-mediated migration steering of colorectal carcinoma. Pathol Oncol Res 25: 559-566, 2019.

26. Xu K, Liu X, Mao X, Xue L, Wang R, Chen L and Chu X MicroRNA-149 suppresses colorectal cancer cell migration and invasion by directly targeting forkhead box transcription factor FOXM1. Cell Physiol Biochem 35: 499-515, 2015.

27. Li LX, Lam IH, Liang FF, Yi SP, Ye LF, Wang JT, Guo WW and Xu M: MiR-198 affects the proliferation and apoptosis of colorectal cancer through regulation of ADAM28/JAK-STAT signaling pathway. Eur Rev Med Pharmacol Sci 23: 1487-1493, 2019.

28. Zhang Z, Zhong X, Xiao Y and Chen C: MicroRNA-296 inhibits colorectal cancer cell growth and enhances apoptosis by targeting ARRB1-mediated AKT activation. Oncol Rep 41: 619-629, 2019

29. Yan F, Tu Z, Duan L, Wang D and Lin F: MicroRNA-383 suppresses cell proliferation and invasion in colorectal cancer by directly targeting paired box 6. Mol Med Rep 17: 6893-6901, 2018.

30. Wang W, He Y, Rui J and Xu MQ: miR-410 acts as an oncogene in colorectal cancer cells by targeting dickkopf-related protein 1 via the Wnt/ $\beta$-catenin signaling pathway. Oncol Lett 17: 807-814, 2019.

31. Li T, Jian X, He H, Lai Q, Li X, Deng D, Liu T, Zhu J, Jiao H, Ye Y, et al: MiR-452 promotes an aggressive colorectal cancer phenotype by regulating a Wnt/ $\beta$-catenin positive feedback loop. J Exp Clin Cancer Res 37: 238, 2018.

32. Li KP,Fang YP, Liao JQ, Duan JD, Feng LG, Luo XZ and Liang ZJ: Upregulation of miR-598 promotes cell proliferation and cell cycle progression in human colorectal carcinoma by suppressing INPP5E expression. Mol Med Rep 17: 2991-2997, 2018.

33. Wang L, Xu M, Lu P and Zhou F: microRNA-769 is downregulated in colorectal cancer and inhibits cancer progression by directly targeting cyclin-dependent kinase 1 . OncoTargets Ther 11: 9013-9025, 2018

34. Yang D, Li R, Xia J, Li W and Zhou H: miR-3666 suppresses cellular proliferation and invasion in colorectal cancer by targeting SATB2. Mol Med Rep 18: 4847-4854, 2018.

35. Liu H, Li D, Fang H and Ning J: Species-specific function of microRNA-7702 in human colorectal cancer cells via targeting TADA1. Am J Transl Res 10: 2579-2589, 2018

36. Mogilyansky E and Rigoutsos I: The miR-17/92 cluster: A comprehensive update on its genomics, genetics, functions and increasingly important and numerous roles in health and disease. Cell Death Differ 20: 1603-1614, 2013.

37. Huang L, Wang X, Wen C, Yang X, Song M, Chen J, Wang C, Zhang B, Wang L, Iwamoto A, et al: Hsa-miR-19a is associated with lymph metastasis and mediates the TNF- $\alpha$ induced epithelial-to-mesenchymal transition in colorectal cancer. Sci Rep 5: 13350, 2015.

38. Hao S, Huo S, Du Z, Yang Q, Ren M, Liu S, Liu T and Zhang G: MicroRNA-related transcription factor regulatory networks in human colorectal cancer. Medicine (Baltimore) 98: e15158, 2019

39. Shirafkan N, Mansoori B, Mohammadi A, Shomali N, Ghasbi M and Baradaran B: MicroRNAs as novel biomarkers for colorectal cancer: New outlooks. Biomed Pharmacother 97: 1319-1330, 2018.
40. Guo Y, Bao Y and Yang W: Regulatory miRNAs in colorectal carcinogenesis and metastasis. Int J Mol Sci 18: 18, 2017.

41. Motoyama K, Inoue H, Takatsuno Y, Tanaka F, Mimori K, Uetake H, Sugihara K and Mori M: Over- and under-expressed microRNAs in human colorectal cancer. Int J Oncol 34: 1069-1075, 2009.

42. Yau TO, Wu CW, Tang CM, Chen Y, Fang J, Dong Y, Liang Q, Ng SS, Chan FK, Sung JJ, et al: MicroRNA-20a in human faeces as a non-invasive biomarker for colorectal cancer. Oncotarget 7: 1559-1568, 2016.

43. Moradi-Marjaneh R, Hassanian SM, Mehramiz M, Rezayi M, Ferns GA, Khazaei M and Avan A: Reactive oxygen species in colorectal cancer: The therapeutic impact and its potential roles in tumor progression via perturbation of cellular and physiological dysregulated pathways. J Cell Physiol 234: 10072-10079, 2019.

44. Zeng X, Xiang J, Wu M, Xiong W, Tang H, Deng M, Li X, Liao Q Su B, Luo Z, et al: Circulating miR-17, miR-20a, miR-29c, and miR-223 combined as non-invasive biomarkers in nasopharyngeal carcinoma. PLoS One 7: e46367, 2012.

45. Yang R, Fu Y, Zeng Y, Xiang M, Yin Y, Li L, Xu H, Zhong J and Zeng X: Serum miR-20a is a promising biomarker for gastric cancer. Biomed Rep 6: 429-434, 2017.

46. Zhu SY, Wu QY, Zhang CX, Wang Q, Ling J, Huang XT, Sun X, Yuan M, Wu D and Yin HF: miR-20a inhibits the killing effect of natural killer cells to cervical cancer cells by downregulating RUNX1. Biochem Biophys Res Commun 505: 309-316, 2018.

47. Li S, Qiang Q, Shan H, Shi M, Gan G, Ma F and Chen B: miR-20a and miR-20b negatively regulate autophagy by targeting RB1CC1/FIP200 in breast cancer cells. Life Sci 147: 143-152, 2016.

48. Fan MQ, Huang CB, Gu Y, Xiao Y, Sheng JX and Zhong L: Decrease expression of microRNA-20a promotes cancer cell proliferation and predicts poor survival of hepatocellular carcinoma. J Exp Clin Cancer Res 32: 21, 2013.

49. Liao C, Chen W and Wang J: MicroRNA-20a regulates glioma cell proliferation, invasion, and apoptosis by targeting CUGBP elav-like family member 2. World Neurosurg 121: e519-e527, 2019.

50. Liu X: Up-regulation of miR-20a by HPV16 E6 exerts growth-promoting effects by targeting PDCD6 in cervical carcinoma cells. Biomed Pharmacother 102: 996-1002, 2018.

51. Zhou L, Li X, Zhou F, Jin Z, Chen D, Wang P, Zhang S, Zhuge Y, Shang Y and Zou X: Downregulation of leucine-rich repeats and immunoglobulin-like domains 1 by microRNA-20a modulates gastric cancer multidrug resistance. Cancer Sci 109: 1044-1054, 2018.

52. Wei L and Ran F: MicroRNA-20a promotes proliferation and invasion by directly targeting early growth response 2 in non-small cell lung carcinoma. Oncol Lett 15: 271-277, 2018.

53. Yu Y, Zhang J, Jin Y, Yang Y, Shi J, Chen F, Han S, Chu P, Lu J, Wang H, et al: MiR-20a-5p suppresses tumor proliferation by targeting autophagy-related gene 7 in neuroblastoma. Cancer Cell Int 18: 5, 2018.

54. Zhao F, Pu Y, Qian L, Zang C, Tao Z and Gao J: MiR-20a-5p promotes radio-resistance by targeting NPAS2 in nasopharyngeal cancer cells. Oncotarget 8: 105873-105881, 2017.

55. Xiong Y, Sun F, Dong P, Watari H, Yue J, Yu MF, Lan CY, Wang Y and MaZB: iASPP induces EMT and cisplatin resistance in human cervical cancer through miR-20a-FBXL5/BTG3 signaling. J Exp Clin Cancer Res 36: 48, 2017.

56. Huang D, Bian G, Pan Y, Han X, Sun Y, Wang Y, Shen G, Cheng M, Fang X and Hu S: MiR-20a-5p promotes radio-resistance by targeting Rab27B in nasopharyngeal cancer cells. Cancer Cell Int 17: 32, 2017.

57. Zhu M, Zhou X, Du Y, Huang Z, Zhu J, Xu J, Cheng G, Shu Y, Liu $\mathrm{P}, \mathrm{Zhu} \mathrm{W}$, et al: miR-20a induces cisplatin resistance of a human gastric cancer cell line via targeting CYLD. Mol Med Rep 14: 1742-1750, 2016.

58. Dhar S, Kumar A, Rimando AM, Zhang X and Levenson AS: Resveratrol and pterostilbene epigenetically restore PTEN expression by targeting oncomiRs of the miR-17 family in prostate cancer. Oncotarget 6: 27214-27226, 2015.

59. Du Y, Zhu M, Zhou X, Huang Z, Zhu J, Xu J, Cheng G, Shu Y, Liu $\mathrm{P}$, Zhu W, et al: miR-20a enhances cisplatin resistance of human gastric cancer cell line by targeting NFKBIB. Tumour Biol 37: 1261-1269, 2016.

60. Wei J, Qi X, Zhan Q, Zhou D, Yan Q, Wang Y, Mo L, Wan Y, Xie D, Xie J, et al: miR-20a mediates temozolomide-resistance in glioblastoma cells via negatively regulating LRIG1 expression. Biomed Pharmacother 71: 112-118, 2015. 
61. Zhao S, Yao D, Chen J, Ding N and Ren F: MiR-20a promotes cervical cancer proliferation and metastasis in vitro and in vivo. PLoS One 10: e0120905, 2015.

62. Zhang Y,Han T, Wei G and Wang Y: Inhibition of microRNA-17/20a suppresses cell proliferation in gastric cancer by modulating UBE2C expression. Oncol Rep 33: 2529-2536, 2015.

63. Zhang X, Kong Y, Xu X, Xing H, Zhang Y, Han F, Li W, Yang Q, Zeng J, Jia J, et al: F-box protein FBXO31 is down-regulated in gastric cancer and negatively regulated by miR-17 and miR-20a. Oncotarget 5: 6178-6190, 2014

64. Zhou J, Liu R, Luo C, Zhou X, Xia K, Chen X, Zhou M, Zou Q, Cao P and Cao K: MiR-20a inhibits cutaneous squamous cell carcinoma metastasis and proliferation by directly targeting LIMK1. Cancer Biol Ther 15: 1340-1349, 2014.

65. Xiong Y, Zhang L and Kebebew E: MiR-20a is upregulated in anaplastic thyroid cancer and targets LIMK1. PLoS One 9: e96103, 2014

66. Xie J, Liu M, Li Y, Nie Y, Mi Q and Zhao S: Ovarian tumor-associated microRNA-20a decreases natural killer cell cytotoxicity by downregulating MICA/B expression. Cell Mol Immunol 11: 495-502, 2014

67. Qiang XF, Zhang ZW, Liu Q, Sun N, Pan LL, Shen J, Li T, Yun C, $\mathrm{Li} \mathrm{H}$ and Shi LH: miR-20a promotes prostate cancer invasion and migration through targeting ABL2. J Cell Biochem 115: 1269-1276, 2014

68. Chang Y, Liu C, Yang J, Liu G, Feng F, Tang J, Hu L, Li L, Jiang F, Chen C, et al: MiR-20a triggers metastasis of gallbladder carcinoma. J Hepatol 59: 518-527, 2013.

69. Bai X, Han G, Liu Y, Jiang H and He Q: MiRNA-20a-5p promotes the growth of triple-negative breast cancer cells through targeting RUNX3. Biomed Pharmacother 103: 1482-1489, 2018.

70. Zhao W, Geng D, Li S, Chen Z and Sun M: LncRNA HOTAIR influences cell growth, migration, invasion, and apoptosis via the miR-20a-5p/HMGA2 axis in breast cancer. Cancer Med 7: $842-855,2018$

71. Yuan G, Zhao Y, Wu D, Gao C and Jiao Z: miRNA-20a upregulates TAK 1 and increases proliferation in osteosarcoma cells. Future Oncol 14: 461-469, 2018.

72. Si W, Shen J, Du C, Chen D, Gu X, Li C, Yao M, Pan J, Cheng J, Jiang D, et al: A miR-20a/MAPK1/c-Myc regulatory feedback loop regulates breast carcinogenesis and chemoresistance. Cell Death Differ 25: 406-420, 2018.

73. Zhao F, Pu Y, Cui M, Wang H and Cai S: MiR-20a-5p represses the multi-drug resistance of osteosarcoma by targeting the SDC2 gene. Cancer Cell Int 17: 100, 2017.

74. Liu L, He J, Wei X, Wan G, Lao Y, Xu W, Li Z, Hu H, Hu Z, Luo X, et al: MicroRNA-20a-mediated loss of autophagy contributes to breast tumorigenesis by promoting genomic damage and instability. Oncogene 36: 5874-5884, 2017.

75. Karimkhanloo H, Mohammadi-Yeganeh S, Ahsani Z and Paryan M: Bioinformatics prediction and experimental validation of microRNA-20a targeting Cyclin D1 in hepatocellular carcinoma. Tumour Biol 39: 1010428317698361, 2017.

76. Shen J, Pan J, Du C, Si W, Yao M, Xu L, Zheng H, Xu M, Chen D, Wang S, et al: Silencing NKG2D ligand-targeting miRNAs enhances natural killer cell-mediated cytotoxicity in breast cancer. Cell Death Dis 8: e2740, 2017.

77. Chen Y, Wang X, Cheng J, Wang Z, Jiang T, Hou N, Liu N, Song $T$ and Huang C: MicroRNA-20a-5p targets RUNX3 to regulate proliferation and migration of human hepatocellular cancer cells. Oncol Rep 36: 3379-3386, 2016.

78. Pu Y, Yi Q, Zhao F, Wang H, Cai W and Cai S: MiR-20a-5p represses multi-drug resistance in osteosarcoma by targeting the KIF26B gene. Cancer Cell Int 16: 64, 2016.

79. Zhang Y, Zheng L, Ding Y, Li Q, Wang R, Liu T, Sun Q, Yang H, Peng S, Wang W, et al: MiR-20a Induces Cell Radioresistance by Activating the PTEN/PI3K/Akt Signaling Pathway in Hepatocellular Carcinoma. Int J Radiat Oncol Biol Phys 92: $1132-1140,2015$

80. Laussmann MA, PassanteE, Hellwig CT, Tomiczek B, Flanagan L, Prehn JH, Huber HJ and Rehm M: Proteasome inhibition can impair caspase-8 activation upon submaximal stimulation of apoptotic tumor necrosis factor-related apoptosis inducing ligand (TRAIL) signaling. J Biol Chem 287: 14402-14411, 2012.

81. Li H, Zhu H, Xu CJ and Yuan J: Cleavage of BID by caspase 8 mediates the mitochondrial damage in the Fas pathway of apoptosis. Cell 94: 491-501, 1998.

82. OrzechowskaEJ,GirstunA,StaronKandTrzcinska-DanielewiczJ: Synergy of BID with doxorubicin in the killing of cancer cells. Oncol Rep 33: 2143-2150, 2015.
83. Eskes R, Desagher S, Antonsson B and Martinou JC: Bid induces the oligomerization and insertion of Bax into the outer mitochondrial membrane. Mol Cell Biol 20: 929-935, 2000.

84.Zhang GJ, Li Y, Zhou H, Xiao HX and Zhou T: miR-20a is an independent prognostic factor in colorectal cancer and is involved in cell metastasis. Mol Med Rep 10: 283-291, 2014

85. Cheng D, Zhao S, Tang H, Zhang D, Sun H, Yu F, Jiang W, Yue B, Wang J, Zhang M, et al: MicroRNA-20a-5p promotes colorectal cancer invasion and metastasis by downregulating Smad4. Oncotarget 7: 45199-45213, 2016.

86. Gonzalez DM and Medici D: Signaling mechanisms of the epithelial-mesenchymal transition. Sci Signal 7: re8, 2014.

87. Longqiu Y, Pengcheng L, Xuejie F and Peng Z: A miRNAs panel promotes the proliferation and invasion of colorectal cancer cells by targeting GABBR1. Cancer Med 5: 2022-2031, 2016.

88. Jiang X, Su L, Zhang Q, He C, Zhang Z, Yi P and Liu J: GABAB receptor complex as a potential target for tumor therapy. J Histochem Cytochem 60: 269-279, 2012.

89. Peters HC, Kämmer G, Volz A, Kaupmann K, Ziegler A, Bettler B, Epplen JT, Sander T and Riess O: Mapping, genomic structure, and polymorphisms of the human GABABR1 receptor gene: Evaluation of its involvement in idiopathic generalized epilepsy. Neurogenetics 2: 47-54, 1998.

90. Yates KE, Korbel GA, Shtutman M, Roninson IB and DiMaio D: Repression of the SUMO-specific protease Senpl induces p53-dependent premature senescence in normal human fibroblasts. Aging Cell 7: 609-621, 2008.

91. Ferlay J, Shin HR, Bray F, Forman D, Mathers C and Parkin DM: Estimates of worldwide burden of cancer in 2008: GLOBOCAN 2008. Int J Cancer 127: 2893-2917, 2010.

92. Melchior F and Hengst L: SUMO-1 and p53. Cell Cycle 1: 245-249, 2002

93. Agostini M, Pucciarelli S, Calore F, Bedin C, Enzo M and Nitti D: miRNAs in colon and rectal cancer: A consensus for their true clinical value. Clin Chim Acta 411: 1181-1186, 2010.

94. Slattery ML, Herrick JS, Pellatt DF, Stevens JR, Mullany LE, Wolff E, Hoffman MD, Samowitz WS and Wolff RK MicroRNA profiles in colorectal carcinomas, adenomas and normal colonic mucosa: Variations in miRNA expression and disease progression. Carcinogenesis 37: 245-261, 2016

95. Tan YG,Zhang YF, Guo CJ, Yang M and Chen MY: Screening of differentially expressed microRNA in ulcerative colitis related colorectal cancer. Asian Pac J Trop Med 6: 972-976, 2013.

96. Bovell L, Shanmugam C, Katkoori VR, Zhang B, Vogtmann E, Grizzle WE and Manne U: miRNAs are stable in colorectal cancer archival tissue blocks. Front Biosci (Elite Ed) 4: 1937-1940, 2012.

97. Pellatt DF, Stevens JR, Wolff RK, Mullany LE, Herrick JS, Samowitz W and Slattery ML: Expression profiles of miRNA subsets distinguish human colorectal carcinoma and normal colonic mucosa. Clin Transl Gastroenterol 7: e152, 2016.

98.Liu X, Xu T, Hu X, Chen X, Zeng K, Sun L and Wang S: Elevated circulating miR-182 acts as a diagnostic biomarker for early colorectal cancer. Cancer Manag Res 10: 857-865, 2018.

99. Emami SS, Akbari A, Zare AA, Agah S, Masoodi M, Talebi A, Minaeian S, Fattahi A and Moghadamnia F: MicroRNA expression levels and histopathological features of colorectal cancer. J Gastrointest Cancer 50: 276-284, 2019

100. Brunet Vega A, Pericay C, Moya I, Ferrer A, Dotor E, Pisa A, Casalots Ä, Serra-Aracil X, Oliva JC, Ruiz A, et al: microRNA expression profile in stage III colorectal cancer: Circulating miR-18a and miR-29a as promising biomarkers. Oncol Rep 30: 320-326, 2013

101. Zhang JX, Song W, Chen ZH, Wei JH, Liao YJ, Lei J, Hu M, Chen GZ, Liao B, Lu J, et al: Prognostic and predictive value of a microRNA signature in stage II colon cancer: A microRNA expression analysis. Lancet Oncol 14: 1295-1306, 2013.

102.Zekri AR, Youssef AS, Lotfy MM, Gabr R, Ahmed OS, Nassar A, Hussein N, Omran D, Medhat E, Eid S, et al: Circulating serum miRNAs as diagnostic markers for colorectal cancer. PLoS One 11: e0154130, 2016.

103. Eslamizadeh S, Heidari M, Agah S, Faghihloo E, Ghazi H, Mirzaei A and Akbari A: The role of microRNA signature as diagnostic biomarkers in different clinical stages of colorectal cancer. Cell J 20: 220-230, 2018.

104. Yang Q, Wang S, Huang J, Xia C, Jin H and Fan Y: Serum miR-20a and miR-486 are potential biomarkers for discriminating colorectal neoplasia: A pilot study. J Cancer Res Ther 14: 1572-1577, 2018. 
105. Yamazaki N, Koga Y, Yamamoto S, Kakugawa Y, Otake Y, Hayashi R, Saito N and Matsumura Y: Application of the fecal microRNA test to the residuum from the fecal occult blood test. Jpn J Clin Oncol 43: 726-733, 2013

106. Rotelli MT, Di Lena M, Cavallini A, Lippolis C, Bonfrate L, Chetta N, Portincasa P and Altomare DF: Fecal microRNA profile in patients with colorectal carcinoma before and after curative surgery. Int J Colorectal Dis 30: 891-898, 2015.

107.Meng F, Henson R, Lang M, Wehbe H, Maheshwari S, Mendell JT, Jiang J, Schmittgen TD and Patel T: Involvement of human micro-RNA in growth and response to chemotherapy in human cholangiocarcinoma cell lines. Gastroenterology 130: 2113-2129, 2006.

108. Xia L, Zhang D, Du R, Pan Y, Zhao L, Sun S, Hong L, Liu J and Fan D: miR-15b and miR-16 modulate multidrug resistance by targeting BCL2 in human gastric cancer cells. Int J Cancer 123: 372-379, 2008.

109. Kovalchuk O, Filkowski J, Meservy J, Ilnytskyy Y, Tryndyak VP, Chekhun VF and Pogribny IP: Involvement of microRNA-451 in resistance of the MCF-7 breast cancer cells to chemotherapeutic drug doxorubicin. Mol Cancer Ther 7: 2152-2159, 2008.

110. Ma J, Dong C and Ji C: MicroRNA and drug resistance. Cancer Gene Ther 17: 523-531, 2010.

111. Li X, Wang H, Wang J, Chen Y, Yin X, Shi G, Li H, Hu Z and Liang X: Emodin enhances cisplatin-induced cytotoxicity in human bladder cancer cells through ROS elevation and MRP1 downregulation. BMC Cancer 16: 578, 2016.

112. Zhang L, He L, Zhang H and Chen Y: Knockdown of miR-20a enhances sensitivity of colorectal cancer cells to cisplatin by increasing ASK1 expression. Cell Physiol Biochem 47: 1432-1441, 2018.

113. Molinari C, Salvi S, Foca F, Teodorani N, Saragoni L, Puccetti M, Passardi A, Tamberi S, Avanzolini A, Lucci E, et al: miR-17-92a-1 cluster host gene (MIR17HG) evaluation and response to neoadjuvant chemoradiotherapy in rectal cancer. Onco Targets Ther 9: 2735-2742, 2016.

114. Azizian A, Kramer F, Jo P, Wolff HA, Beißbarth T, Skarupke R, Bernhardt M, Grade M, Ghadimi BM and Gaedcke J: Preoperative prediction of lymph node status by circulating mir-18b and mir-20a during chemoradiotherapy in patients with rectal cancer. World J Surg 39: 2329-2335, 2015.

115. Jo P, Azizian A, Salendo J, Kramer F, Bernhardt M, Wolff HA Gruber J, Grade M, Beißbarth T, Ghadimi BM, et al: Changes of microrna levels in plasma of patients with rectal cancer during chemoradiotherapy. Int J Mol Sci 18: 18, 2017.

116. Okugawa Y, Toiyama Y and Goel A: An update on microRNAs as colorectal cancer biomarkers: Where are we and what's next? Expert Rev Mol Diagn 14: 999-1021, 2014

117.Zhang J, Zhang K, Bi M, Jiao X, Zhang D and Dong Q: Circulating microRNA expressions in colorectal cancer as predictors of response to chemotherapy. Anticancer Drugs 25 346-352, 2014.

118. Xie T, Li Y, Li SL and Luo HF: Astragaloside IV enhances cisplatin chemosensitivity in human colorectal cancer via regulating NOTCH3. Oncol Res 24: 447-453, 2016.

119. Ma MZ, Chen G, Wang P, Lu WH, Zhu CF, Song M, Yang J, Wen S, Xu RH, Hu Y, et al: Xc- inhibitor sulfasalazine sensitizes colorectal cancer to cisplatin by a GSH-dependent mechanism. Cancer Lett 368: 88-96, 2015.

120. Aouacheria A, Brunet F and Gouy M: Phylogenomics of life-or-death switches in multicellular animals: Bcl-2, BH3-Only, and BNip families of apoptotic regulators. Mol Biol Evol 22: 2395-2416, 2005.

121. Chai H, Liu M, Tian R, Li X and Tang H: miR-20a targets BNIP2 and contributes chemotherapeutic resistance in colorectal adenocarcinoma SW480 and SW620 cell lines. Acta Biochim Biophys Sin (Shanghai) 43: 217-225, 2011.
122. Ashrafizadeh M, Ezzati H, Ahmadi Z, Farkhondeh T and Samarghandian S: Anti-tumor activity of propofol: A focus on microRNAs. Curr Cancer Drug Targets 19: 2019. https://doi.org/ 10.2174/1568009619666191023100046

123. Ji R, Zhang X, Gu H, Ma J, Wen X, Zhou J, Qian H, Xu W, Qian J and Lin J: miR-374a-5p: A New Target for Diagnosis and Drug Resistance Therapy in Gastric Cancer. Mol Ther Nucleic Acids18: 320-331, 2019

124. Luo X, Burwinkel B, Tao S and Brenner H: MicroRNA signatures: Novel biomarker for colorectal cancer? Cancer Epidemiol Biomarkers Prev 20: 1272-1286, 2011.

125. Caritg O, Navarro A, Moreno I, Martínez-Rodenas F, Cordeiro A, Muñoz C, Ruiz-Martinez M, Santasusagna S, Castellano JJ and Monzó M: Identifying high-risk stage II colon cancer patients: A three-microRNA-based score as a prognostic biomarker. Clin Colorectal Cancer 15: e175-e182, 2016.

126. Schetter AJ, Leung SY, Sohn JJ, Zanetti KA, Bowman ED, Yanaihara N, Yuen ST, Chan TL, Kwong DL, Au GK, et al: MicroRNA expression profiles associated with prognosis and therapeutic outcome in colon adenocarcinoma. JAMA 299: 425-436, 2008.

127. Pesta M, Kucera R, Topolcan O, Karlikova M, Houfkova K, Polivka J, Macanova T, Machova I, Slouka D and Kulda V: Plasma microRNA levels combined with CEA and CA19-9 in the follow-up of colorectal cancer patients. Cancers (Basel) 11: 11, 2019.

128. Gandhy SU, Kim K, Larsen L, Rosengren RJ and Safe S: Curcumin and synthetic analogs induce reactive oxygen species and decreases specificity protein $(\mathrm{Sp})$ transcription factors by targeting microRNAs. BMC Cancer 12: 564, 2012.

129. Choi JB, Kim JH, Lee H, Pak JN, Shim BS and Kim SH: Reactive Oxygen Species and p53 Mediated Activation of p38 and Caspases is Critically Involved in Kaempferol Induced Apoptosis in Colorectal Cancer Cells. J Agric Food Chem 66: 9960-9967, 2018.

130. Pehserl AM, Ress AL, Stanzer S, Resel M, Karbiener M, Stadelmeyer E, Stiegelbauer V, Gerger A, Mayr C, Scheideler M, et al: Comprehensive Analysis of miRNome Alterations in Response to Sorafenib Treatment in Colorectal Cancer Cells. Int J Mol Sci 17: 17, 2016.

131. Li R, Jiang J, Shi H, Qian H, Zhang X and Xu W: CircRNA: A rising star in gastric cancer. Cell Mol Life Sci, 2019. https://doi. org/10.1007/s00018-019-03345-5.

132. Su Q and Lv X: Revealing new landscape of cardiovascular disease through circular RNA-miRNA-mRNA axis. Genomics S0888-7543(19)30565-8, 2019

133. Xiu Y, Jiang G, Zhou S, Diao J, Liu H, Su B and Li C: Identification of potential immune-related circRNA-miRNA-mRNA regulatory network in intestine of paralichthys olivaceus during Edwardsiella tarda infection. Front Genet 10: 731, 2019.

134. Ping L, Jian-Jun C, Chu-Shu L, Guang-Hua L and Ming Z: Silencing of circ 0009910 inhibits acute myeloid leukemia cell growth through increasing miR-20a-5p. Blood Cells Mol Dis 75: 41-47, 2019.

135. Salmena L, Poliseno L, Tay Y, Kats L and Pandolfi PP: A ceRNA hypothesis: The Rosetta Stone of a hidden RNA language? Cell 146: 353-358, 2011.

136.Zhang X, Wu N, Wang J and Li Z: LncRNA MEG3 inhibits cell proliferation and induces apoptosis in laryngeal cancer via miR-23a/APAF-1 axis. J Cell Mol Med 23: 6708-6719, 2019.

137. Huang QR and Pan XB: Prognostic lncRNAs, miRNAs, and mRNAs form a competing endogenous RNA network in colon cancer. Front Oncol 9: 712, 2019.

(c) (i) (-) $€$ This work is licensed under a Creative Commons cc) $\mathrm{EY}$ No ND Attribution-NonCommercial-NoDerivatives 4.0 International (CC BY-NC-ND 4.0) License. 